\title{
CONTEXTOS QUE HABLAN. REVISIONES DEL VÍNCULO GÉNERO/JUVENTUD: DEL CASO MARÍA SOLEDAD AL \#NIUNAMENOS
}

Silvia Elizalde ${ }^{1}$

\section{RESUMEN}

¿Qué pudo ser "visto" por el campo de los estudios de juventud en relación con las diferencias de género y sexualidad hace veinticinco años, y qué puede ser observado ahora? ¿Qué no pudo leerse entonces o ahora sí en esas claves, y/o viceversa, y por qué? ¿Cómo se fue moldeando esa mirada? ¿Qué relación guardó o aún guarda con las operaciones de inteligibilidad de estas mismas distinciones en la agenda social más extendida? ¿Cómo resuena todo esto hoy en nuestras decisiones teóricas, investigativas y de compromiso intelectual con los/as jóvenes?

Con estos interrogantes como guía, a continuación exploro dos acontecimientos que conmovieron la vida social argentina en los extremos de las últimas dos décadas y media -uno, a comienzos de los ' 90 y otro, con resonancias en el presente- en tanto "puertas de entrada" a coyunturas culturales, políticas e históricas específicas. El propósito es analizar algunas de las condiciones de

1 Doctora en Antropología (Universidad de Buenos Aires) e Investigadora Independiente del CONICET, con sede en el Instituto Interdisciplinario de Estudios de Género, de la Facultad de Filosofía y Letras, UBA. Directora del Programa de Actualización en Comunicación, Géneros y Sexualidades, de la Facultad de Ciencias Sociales, UBA. Correo electrónico: silvitaelizalde@gmail.com 
posibilidad y articulación que hicieron -o no- públicamente "visible" el vínculo entre género y juventud en cada momento, así como los significados y alcances que asumieron estas diferencias críticas para la investigación en juventudes. La meta más amplia es señalar algunas coordenadas conceptuales y políticas en torno de una perspectiva contextual para este ámbito de saber e insistir en la importancia insoslayable de una interrogación feminista para encarar algunos de los desafíos teóricos y epistemológicos que tenemos por delante.

PALABRAS CLAVE: ESTUDIOS EN JUVENTUDES, PERSPECTIVA CONTEXTUAL, FEMICIDIOS, MUJERES JÓVENES, TEORÍA FEMINISTA, MARIA SOLEDAD MORALES, \#NIUNAMENOS

\section{CONTEXTOS QUE FALAM. REVISÕES DO VÍNCULO GÊNERO/JUVENTUDE: DO CASO MARÍA SOLEDAD AO \#NIUNAMENOS}

\section{RESUMO}

O que pôde ser "olhado" pelo campo dos estudos de juventude em relação às diferenças de gênero e sexualidade há vinte e cinco anos, e o que pode ser observado agora? O que não pôde ser lido então e agora sim nessas chaves, e/ou vice-versa, e por quê? Como foi moldado este olhar? Que relação teve ou ainda tem com as operações de inteligibilidade destas mesmas distinções na agenda social mais extensa? Como tudo isto ressoa hoje em nossas decisões teóricas, de pesquisa e de compromisso intelectual com os e as jovens?

Com estas perguntas como um guia, a continuação exploro dois eventos que comoveram a vida social argentina nos extremos das últimas duas décadas e meia - um, no início dos anos go e o outro, com ressonâncias no presente considerados "portas de entrada" para conjunturas culturais, políticas e históricas específicas. O objetivo é analisar algumas das condições de possibilidade e articulação que tornaram - ou não- publicamente "visível" o vínculo entre gênero e juventude o tempo todo, bem como os significados e alcances que assumiram estas diferenças críticas para a pesquisa em juventudes. O objetivo mais amplo é apontar algumas coordenadas conceituais e políticas em torno de uma perspectiva contextual para essa área do conhecimento e insistir na importância inegável de uma interrogação feminista para enfrentar alguns dos desafios teóricos e epistemológicos que estão por vir.

PALAVRAS-CHAVE: ESTUDOS DE JUVENTUDE, PERSPECTIVA CONTEXTUAL, FEMICÍDIOS, MULHERES JOVENS, TEORIA FEMINISTA, MARÍA SOLEDAD MORALES, \#NIUNAMENOS 


\title{
CONTEXTS THAT SPEAK: REVISIONS OF THE GENDER/ YOUTH LINK: FROM THE MARÍA SOLEDAD CASE TO \#NIUNAMENOS
}

\begin{abstract}
What aspects regarding gender and sexuality differences could have been "observed" by youth studies twenty-five years ago, and which ones can be observed today? What aspects could not be read from those codes that are read nowadays, and/or vice versa, and why? How has this perspective been molded? What is its former or current relationship with the intelligibility operations of these same distinctions in the most extended social agenda? How does this resonate today on our theoretical, investigative and intellectual commitment decisions regarding young male and female young people?

From these guidelines, I will look into two shocking events for the Argentinian social life that took place in the extremes of the last two and a half decades; both events, the first of them in the early gos and the other one, still contemporary, have acted as gateways for specific cultural, political and historical conjunctions. The purpose of this article is to analyze some of the articulation and possibility conditions enabling - or preventing - the public visualization of the link between gender and youth at each moment, as well as the meanings and scopes these critical differences have implied for research on youths. In general terms, it is intended to point out certain conceptual and political coordinates towards a contextual perspective in order to know, and stress on, the inescapable need for a feminist inquiry to face some of the theoretical and epistemological challenges to be found on the way.
\end{abstract}

KEYWORDS: YOUTH STUDIES, CONTEXTUAL PERSPECTIVE, FEMICIDES, YOUNG WOMEN, FEMINIST THEORY, MARIA SOLEDAD MORALES, \#NIUNAMENOS

\section{COORDENAS GENERALES Y DEL PROPIO LUGAR}

A comienzos de la década de 1990 y en pleno auge de un ciclo indisimuladamente neoliberal en los países del Cono Sur, el campo de los estudios de juventud -por entonces denominado así, en singular- tomaba un decidido impulso en los ámbitos institucionales de producción de conocimiento, los foros regionales promovidos por organismos internacionales dedicados al sector, y en la industria editorial orientada a las ciencias sociales. Un lustro antes, la Organización de Naciones Unidas había declarado a I985 como el Año Internacional 
de la Juventud. Daba así apertura formal a una trayectoria de trabajos de investigación, intervención y de política pública que, en la América Latina de la reapertura democrática y en relación con las diferencias de géneros y sexualidades que aquí nos ocupan, recorrería desde entonces el espesor de transformaciones impactantes en la malla cultural y política de nuestros países.

A principios de 1990 yo tenía I8 años y empezaba la universidad pública en una ciudad de escala intermedia de la provincia de Buenos Aires, en la Argentina. Cinco años más tarde me recibía con una tesis sobre representaciones mediáticas de la juventud pobre en aquel centro urbano con un trabajo titulado "El joven bajo sospecha". En mi país eran tiempos de indagación, prioritariamente sociológica, alrededor de la figura del "pibe chorro" como signo emergente y condensación de sentidos de un contexto de aguda crisis económica, cuyos impactos se advertían en una creciente profundización de la pobreza, la exclusión de amplios sectores sociales de sus derechos básicos y respuestas represivas del Estado focalizadas en ciertos grupos y colectivos. En lunfardo², "chorro" es sinónimo de ladrón, pero la denominación de "pibe chorro" no se aplicaba por entonces -ni ahora- solo o exclusivamente a jóvenes que hubiesen delinquido sino de manera ubicua a los jóvenes varones, pobres y de los suburbios sobre los cuales los "imaginarios sociales entrenados en la descalificación" (Rodríguez Alzueta, 20I4:Io6) habían delineado apriorísticamente los contornos del caos, la anomia y el vandalismo moral (Kessler, 2004; Míguez, 2004; Sergio Tonkonof 2007; Mariana Chaves, 2018). Con esas lecturas sociológicas en mente y con la revisión de los señeros trabajos de fines de los 70 de Stuart Hall, Stanley Cohen y otros, reunidos en Policing the Crisis (1979), sobre los jóvenes migrantes de las afueras de Londres y los pánicos morales construidos en su entorno en tiempos del thatcherismo, había trazado los argumentos principales de mi tesis, para licenciarme. Allí me había propuesto analizar los modos históricos de articulación de la desigualdad económica con la distinción de clase y edad en la producción de subjetividades "peligrosas" asociadas a los jóvenes de aquella ciudad bonaerense. Para ello indagaba la relación entre la institucionalización colectiva de imágenes de violencia juvenil y la exhibición mediática de la experiencia privada como condiciones que participaban tanto de la elaboración de retóricas mediales específicas sobre la "peligrosidad juvenil" como de definiciones puntuales de la crisis en términos culturales. En las conclusiones advertía -un tanto tibiamente, a los ojos contemporáneos-, sobre la ausencia, en esas textualidades periodísticas, de representaciones juveniles femeninas en posiciones de agencia y/o en ejercicio de prácticas con despliegue público. Y, de manera simultánea, sobre su "aparición" mediática desde la siempre disponible posición de "víctimas" a las que tan frecuentemente el poder ha ubicado a las

2 Jerga rioplatense nacida de la fusión de palabras extranjeras, en el contexto de la inmigración de fines del siglo XIX y principios del XX, aún vigente en el habla coloquial y en numerosas letras de tango. 
mujeres como condición unívoca de su visibilidad social.

En efecto, el análisis de las "representaciones sociales" y la focalización en los varones jóvenes como sinónimo universalizante de "la juventud" eran clivajes recurrentes en las investigaciones de aquellos años, junto con el estudio de las "culturas juveniles", no solo en la Argentina sino en buena parte del Continente. La coyuntura política y cultural más amplia parecía habilitar el recorte de los objetos de estudio en las "resistencias", los estilos "contraculturales" y el agrupamiento en "tribus" de las nuevas generaciones. En paralelo, la naturalizada ubicuidad del androcentrismo en la lente sociológica y de otras disciplinas sociales (Elizalde, 2006 y 20I4; Duarte, 20II, 20I5 y 20I8; Alvarez, 20I8) impedía la revisión crítica de la hoy impensable invisibilización y subalternización desembozadas que por entonces se ejercía sobre las chicas y el arco variado de identidades sexogenéricas juveniles existentes, incluso en el corpus mismo de las indagaciones académicas sobre este colectivo.

Defendí aquella tesis a los 23 años, en I995, dos años después de la creación de Última Década, sin dudas la más "antigua" y sistemática publicación académica centrada en los estudios de juventud en la Región. La misma que hoy me convoca a desandar reflexivamente el paso de dos décadas y media -su propio tiempo de existencia- en el interpelante campo de los géneros y las sexualidades asociados a las juventudes, ahora sí, en plural.

\section{HOJA DE RUTA}

Con este convite como oportunidad y desafío 3 , en lo que sigue me propongo revisar dos coyunturas históricas que actuaron como condiciones de posibilidad para la formulación de preguntas sobre el lugar de estas diferencias críticas en la vida de los y las jóvenes por parte de la agenda social, y de la enunciación científica especializada en juventudes. Dichas coyunturas se ubican en sendos extremos del arco temporal de estos últimos veinticinco años: la primera, a principios de la década del '9o y la otra, en el presente, compartiendo ambas -con sus respectivas especificidades- las marcas lacerantes que imprimen el neoliberalismo y el retroceso de las responsabilidades del Estado en la vida social, y los impactos y las conflictividades que esto supone en la matriz cultural de las sociedades, las prácticas de resistencia y el ejercicio de derechos. Asimismo, procuro relevar el tipo de interpelación que esos interrogantes plantearon y/o plantean al propio saber académico y a sus hacedores/as respecto de dos ejes

3 Agradezco a Klaudio Duarte y al equipo de la revista la generosidad de invitarme a sumar una reflexión sobre las juventudes y el ámbito académico que se ocupa de estudiarlas, desde la especificidad de mi campo de especialización, para este número aniversario de Última Década. Es un convite que me honra y un motivo de celebración compartida por los veinticinco años de esta importante publicación. A Klaudio, especialmente, le agradezco también la confianza, la infinita paciencia y la tácita complicidad que nos hermana en nuestra lucha cotidiana contra el patriarcado. 
recursivos e interconectados:

a) las operaciones de iluminación/difuminado de la diferencia de género y sexualidad en la producción de conocimiento sobre esas experiencias y prácticas juveniles, y los aportes posibles de una crítica feminista a estos asuntos;

b) nuestra posicionalidad -como intelectuales y/o cientistas sociales- en relación con las transformaciones culturales y políticas ocurridas en la trama de relaciones y derechos vinculados con las configuraciones sexogenéricas, y sus resonancias en las juventudes en los últimos veinticinco años.

El propósito más amplio no es producir un balance, un diagnóstico o un estado de la cuestión sobre estas materias en el campo de los estudios en juventudes en América Latina, configuración sociohistórica y geográfica amplísima, por otra parte, que requeriría de un ejercicio reductivo extremo para encajar en una descripción englobadora respecto de estos temas, y que excede por completo mis posibilidades y pretensión en este escrito. Me guía, más bien, la intención de sugerir la inscripción de estas preguntas en un campo problemático cuyo núcleo no hable de "los géneros", "las sexualidades" y "las juventudes", sino de formaciones sociales (Williams, I977) y de contextos sociales específicos, que están ya sexualizados y generizados de un modo situado. Y en cuyas condiciones, también específicas e históricamente desiguales -respecto de los/as adultos, los/as pares y las instituciones que traman sus experiencias biográficas y colectivas-, las chicas y los chicos despliegan prácticas concretas, performan sus cuerpos y gestionan sus vidas de relación.

No es, pues, mi interés revisar aquí cómo unas ciertas prácticas, procesos o experiencias juveniles desplegados en interconexión con las diferencias de géneros y sexualidades en algunas de sus muchas expresiones se convirtieron, en estos últimos veinticinco años, en "temas" de investigación sobre estos cruces o desde qué perspectivas. Tampoco indagar en cuáles casos fueron abordados reductivamente como correspondencias directas o "evidencias" verificadoras de un determinado modo de funcionamiento ideológico en una u otra sociedad (por ejemplo, como "indicadores" de violencia patriarcal, como manifestaciones del sexismo; o como formas de reconocimiento social de las sexualidades disidentes, entre otras). La invitación, en cambio, es a explorar dichos materiales de la experiencia concreta de las y los jóvenes como "puerta de entrada" a una específica coyuntura cultural, política e histórica (Grossberg, 2012, p. 43). Es decir, a un contexto material, cambiante y específico, entendido como una articulación compleja de fuerzas críticas y de relaciones entre prácticas que "rodean [esos materiales experienciales], los interpenetran y los convierten en lo que son" (p.36).

En este sentido, los acontecimientos, las prácticas o las experiencias juveniles que en determinado momento se invisten de ciertos sentidos de orden sexual, corporal y/o de género no serían, en rigor, los objetos centrales de este 
estudio. Más bien el foco está puesto en las condiciones de producción y en las relaciones desiguales de fuerza y poder que en cada coyuntura han tramado esas investiduras semánticas, las han fijado, desplazado y/o rearticulado con otras prácticas, sentidos y valores; las han iluminado, invisibilizado y/o gestionado en cierto momento de modos concretos. De allí también la importancia, en este enfoque, de interrogar simultáneamente los contextos y la propia mirada del/la investigador/a que recorta, y en ese sentido, "produce" esos materiales, para explorarlos.

Finalmente, aclaro que no puedo sino asumir un punto de vista local, con foco en mi país, aunque con aspiración a su puesta en diálogo con las reflexiones que se vienen haciendo sobre estos cruces en los estudios en juventudes de otras geografías del Continente. No sólo porque es el contexto en el que investigo y sobre el que reflexiono, sino porque en estas últimas dos largas décadas -en coincidencia casi con la finalización de aquella tesis de grado- mi camino de formación e investigación ha sido atravesado por muy distintas condiciones institucionales de posibilidad y restricción. Tanto en relación con el trabajo intelectual y la producción de conocimiento como, y sobre todo, con las preguntas que el propio contexto fue presentando respecto del lugar de las diferencias de géneros y sexualidades en las trayectorias vitales de las nuevas generaciones. En parte esto explica el pasaje de aquel primer interés en las representaciones mediáticas de los varones pobres urbanos -que no era solo individual sino muy extendido en los trabajos sobre juventud a inicios de los ' 90 - a las exploraciones etnográficas sobre géneros y sexualidades que desde hace un tiempo vienen teniendo tanta centralidad en nuestros ámbitos de estudio, donde las mujeres son incluso, por sobre los varones, el foco prioritario de esas indagaciones, en tanto protagonistas principales de un cambio cultural en curso.

Me moviliza, pues, la inquietud por explorar qué condiciones y qué preguntas provenientes de cada una de esas coyunturas hicieron posible esos tránsitos y refocalizaciones. Esto es: ¿qué pudo ser "visto" por el campo de los estudios de juventud y por la agenda social más amplia en relación con las diferencias de género y sexualidad hace veinticinco años, y qué puede ser observado ahora? ¿Qué no pudo leerse entonces y ahora sí en esas claves, y/o viceversa, y por qué? ¿Cómo se fueron moldeando esas miradas? ¿Cómo resuena todo esto hoy en nuestras decisiones teóricas, investigativas y de compromiso intelectual con los/as jóvenes, y en la concreta materialidad de nuestro trabajo?

No usaré, por supuesto, una lente autorreferencial para responder estas cuestiones. Procuraré, más bien, revisar en los dos contextos mencionados ubicados respectivamente, como indiqué, en los inicios y en el tiempo presente de esta Revista, que es también el lapso temporal mi propio trabajo investigativo sobre juventudes-, algunas de las condiciones históricas de posibilidad y articulación de las diferencias sexo-genéricas con la edad, en relación con este colectivo. La idea, a partir de allí, es dejar planteadas algunas coordenadas conceptuales y políticas en torno de esta perspectiva contextual e insistir, una 
vez más, en la importancia insoslayable y estratégica de una interrogación feminista para encarar algunos de los desafíos teóricos y epistemológicos que tenemos por delante.

\section{EL GÉNERO Y LA EDAD COMO DIFERENCIAS “DIFUSAS”}

En septiembre de i99o una chica de clase media baja, de la ciudad Catamarca, capital de la provincia homónima, en el noroeste argentino, apareció muerta al costado de una ruta, a pocos kilómetros de ese centro urbano. Su cuerpo estaba completamente desfigurado, quemado con cigarrillos y fracturado. La autopsia confirmó después que su interior estaba saturado de cocaína y que había sufrido reiteradas violaciones. Tenía i7 años, era la segunda de siete hermanos de una familia humilde y cursaba el último año de una escuela secundaria católica. Se llamaba María Soledad Morales y dos días antes del hallazgo había ido a una fiesta organizada por compañeras de su colegio para juntar fondos para pagarles el viaje de egresadas a cinco alumnas que no podían costearse los gastos, una de las cuales era ella.

La secuencia trágica de violencias que terminó en su muerte casi podría ser la de tantas otras mujeres jóvenes asesinadas en la Argentina y en otros países latinoamericanos. Pero su muerte significó mucho más. Operó como "puerta de entrada" para leer un contexto político y cultural cuyas articulaciones internas entre prácticas, valoraciones de orden moral y significaciones sociales -sobre los varones jóvenes ricos e impunes, las chicas "sencillas", los cuerpos legítimos y los cuerpos descartables, etc.- perdieron contingentemente cohesión y fijeza de sentido, como la misma alianza de fuerzas opresivas que les daba sustento. En un giro imprevisible de condiciones materiales y simbólicas, dicho campo semántico -que reunía naturalizadoramente términos como "élites políticas, corrupción, masculinidades hegemónicas, modelos de autoridad [y] relaciones de género" (Gayol y Kessler, 20I8, p. II6)- recibió el embate de su puesta en evidencia, y estalló bajo la forma de crisis de legitimidad política.

En efecto, casi inmediatamente a la aparición del cuerpo se supo que María Soledad había sido entregada por su novio a un grupo de jóvenes pertenecientes a familias del poder político de Catamarca, que la drogaron, violaron y arrojaron muerta en las afueras de la ciudad 4 . La investigación estuvo viciada

4 Por el caso fueron detenidos y condenados, tras la realización de dos juicio orales, dos hombres: Guillermo Luque (hijo de un diputado nacional) y Luis Tula, por entonces novio de María Soledad pese a que estaba casado con otra mujer, por ser el entregador de la joven a Luque. También fueron sospechados Pablo y Diego Jalil, hijos del intendente de aquella ciudad, "Arnoldito" Saadi, sobrino del gobernador, y Miguel Ferreyra, hijo del jefe de la Policía provincial, que acompañaban a Luque. Todos ellos fueron sobreseídos. Luque fue condenado a 21 años de cárcel como co-autor de asesinato y violación (salió en libertad condicional cumplidos 14 de su condena, por "buena conducta") y Tula a 9 años como partícipe secundario de violación. En la cárcel estudió Derecho y tras cumplir su pena, fue liberado y desde entonces ejerce como abogado penal en la capital provincial. Se constató que en la violación y desfiguración del cuerpo de la joven habían intervenido 
desde el inicio y la cadena de encubrimientos involucró a funcionarios municipales, provinciales y nacionales. Se supo, por ejemplo, que el Jefe de la Policía de la provincia y padre de uno de los integrantes de la cofradía juvenil masculina que participó de la fiesta privada donde la chica fue abusada, mandó a lavar inmediatamente el cadáver, tras su hallazgo, lo cual borró pistas fundamentales para la reconstrucción de lo ocurrido ${ }^{5}$. Por su parte, el padre del principal acusado, por entonces diputado de la Nación, llegó a decirle a un periodista una frase que le costó su desafuero, pero que, sobre todo, condensó parte significativa de la configuración de dominio de aquella coyuntura: "Si mi hijo hubiera matado a esa pobre criatura, yo le juro que ese cadáver no aparece nunca más" (La Nación, 27/7/2018, digital). En los ocho años posteriores al crimen hubo dos juicios por los que pasaron más de 300 testigos y i4 jueces, y se constató que todos fueron sometidos a distintas presiones. El caso recibió cobertura periodística nacional e internacional durante años. La conmoción que despertó la muerte de la joven y, como veremos enseguida, la presión popular en reclamo de justicia, motivaron la intervención federal de Catamarca, que marcó el fin, siete meses después del crimen, de la casta política que regía los destinos de aquella provincia desde hacía cuatro décadas, encabezada por la familia Saadi.

Sin dudas, la muerte de María Soledad produjo un impacto profundo y duradero en la sociedad argentina. No es intención de este artículo revisar todas sus connotaciones, que fueron y son muchas, ni reponer las agudas lecturas sociológicas que se realizaron recientemente respecto de ésta y otras muertes que, "por los cambios que motorizaron y por su capacidad de plantear nuevos problemas, nutrieron a la democracia de nuevos contenidos y significados, y contribuyeron a reconfigurar la sociedad argentina" (Gayol y Kessler, 20I8, p. I2). Se trata, más bien, de interrogarnos por las condiciones que hicieron posible que el caso asumiera un carácter eminentemente "político", en detrimento de un estatuto que enfatizara las diferencias de género, sexualidad y edad, fuertemente involucradas en este suceso. En efecto, pese a tratarse de la violación y el asesinato de una adolescente y de haberse constatado la aplicación de formas crueles y degradantes sobre la chica, reducida a objeto de consumo sexual por parte de un grupo de varones jóvenes que actuaron amparados por la impunidad del poder político y patriarcal, el caso no fue codificado masivamente como crimen sexual ni resaltado especialmente el vínculo entre género y edad como articulación conflictiva. Más bien dichas diferencias quedaron "difuminadas" en la opinión pública y mediática, así como en el propio campo de estudios de juventud -por entonces en plena ebullición y crecimiento-, a juzgar por la ausencia total de estudios sobre esta muerte en alguno de estos clivajes culturales,

al menos dos personas, pero el o los co-autores del crimen nunca fueron identificados.

5 Fue el mismo que, mientras la familia de la chica reclamaba justicia, aconsejó a la comunidad de padres de adolescentes tener "más control sobre sus hijos". Y añadió: “deben saber quiénes son sus amigos y compañeros. Conocer los lugares a los que concurren y no dejarlos a la deriva. Es fundamental para su seguridad" (Clarín, 11/9/1990, s/p). 
o en cualquier otro en dicho ámbito ${ }^{6}$. El término preciso que permitiría poner el suceso en una clave de género en la agenda social más amplia -"femicidio"vino después. Incluso, mucho años después, en 2012, de la mano del feminismo, de su trabajo de incidencia para incorporarlo al código penal argentino, en reemplazo de la figura de "homicidio en estado de emoción violenta" aplicado a casos de violencia de género, y de un proceso creciente de tematización social, mediática y académica de las transformaciones operadas en el campo de las configuraciones sexogenéricas.

En este punto nos interesa insistir en una proposición, que es a la vez una invitación a revisar los presupuestos epistemológicos con los que se piensa frecuentemente el vínculo entre género y juventud. Al respecto, remarcamos que atender a lo que los contextos "dicen" requiere algo más que asir los contornos que enmarcan a un conjunto de prácticas. Implica, más bien, delinear la configuración que rodea y constituye a dichas prácticas. En relación con nuestro campo de interés esto quiere decir que no se trata tanto de leer la dimensión de género y sexualidad asociada a las y los jóvenes en prácticas o acontecimientos puntuales que en un tiempo específico se "tiñen" expresamente de esas distinciones, sino de hacerlo a partir de ellos. Esto es, en el marco de las relaciones preexistentes y de los desplazamientos de sentido que construyen la argamasa dinámica de la coyuntura en la que ocurren y que permiten relevar los modos en que en dicha formación social las diferencias de género y sexualidad se articulan ente sí y con otros clivajes de poder -como la clase, la edad, la relación con los adultos, etc. Pero también, como ocurrió en el caso María Soledad, con otros elementos fundamentales, como la política y los políticos, el sistema judicial y la policía, el lugar de la escuela y la moral católica en la socialización de las mujeres jóvenes en ese enclave urbano, el nepotismo en la distribución de los recursos y privilegios en aquella provincia del norte, y los propios sentidos comunitarios sobre la justicia, la dignidad de los pobres y los reclamos de verdad que circularon entonces en Catamarca alrededor del homicidio de la joven.

Así, en aquella coyuntura cobraron importancia prácticas y actores que, en relación con el orden dado, desencadenaron cambios que modificaron la malla de inteligibilidad de las significaciones hegemónicas sobre "la muerte", los "privilegios" del poder, la "docilidad" de los subalternos, y el propio signifi-

6 De acuerdo con las búsquedas que emprendí para este artículo y la consulta que realicé a lxs más de 300 colegas que integran el mailing de la Red Nacional de Investigadores/ as en Juventudes Argentina (ReIJA), no se han realizado en este país análisis académicos específicos sobre el caso María Soledad inscriptos en el campo de los estudios en juventudes. El único antecedentes que puede anotarse en este ámbito es una breve reflexión de la historiadora Valeria Manzano (2011) contenida en un artículo recuperado más adelante en el presente texto (agradezco el dato a Pedro Nuñez), y una también breve mención mía, en el marco de una contextualización más amplia sobre modos de figuración de las mujeres jóvenes en su condición de "víctimas" en la Introducción a mi libro Tiempo de chicas (2015). Agradezco también a Rodolfo Nuñez, colega de la ReIJA, por la temprana indicación del libro de Gayol y Kessler (2018), que se publicó casi en paralelo a la escritura de este artículo. 
cado diferencial de "la juventud" aplicada a la víctima y aquella reservada a los "hijos del poder". A sólo cuatro días de encontrar sin vida a María Soledad, la monja carmelita Martha Pelloni, rectora del colegio religioso al que iba la chica, organizó una marcha en reclamo de justicia, junto a los padres de la víctima y sus compañeras/os de escuela. Recorrieron las calles céntricas de la ciudad sin cantos, música, gritos ni vociferaciones, bajo el argumento, aún difuso, de que "el silencio puede más que la violencia". De hecho la caminata fue bautizada por el periodismo como "Marcha del Silencio" e inauguró un ciclo que se desplegaría en Catamarca -allí hubo 50 marchas solo en el primer año desde la aparición del cuerpo, y 83 en total (La Gaceta, 9/9/2005) -, con réplicas en varias ciudades del país y durante varios años. El fenómeno dio forma a una modalidad de protesta inédita hasta entonces en la Argentina, que de ahí en más fue adoptada por un arco variado de causas y actores en sus repertorios de movilización. Si la primera había sido numerosa -unos/as 7000 manifestantes-, las siguientes fueron multitudinarias, llegando a ser 30.000 las personas que tomaron las calles de la capital de la provincia norteña, movidas por la rabia ante la impunidad y el entramado corrupto que impedía la investigación del crimen, y pidiendo pacíficamente por su esclarecimiento, en un efectivo mecanismo de presión popular sobre el poder político.

Es interesante resaltar que, además de la monja y de los padres de María Soledad, fueron las y los estudiantes secundarios de escuelas tanto privadas como públicas quienes acompañaron masivamente estas marchas -para algunos/as, incluso, quienes "lideraron la indignación" (Manzano, 20II, p.48). Esto dio por tierra con el extendido argumento de que la última década del siglo XX estuvo signada en la Argentina por la desmovilización estudiantil. La historiadora Valeria Manzano, de hecho, considera que las Marchas del Silencio desplegadas en torno de este caso fueron una de las tres instancias decisivas que articularon el movimiento estudiantil en este país, en el despunte de los '9o (20Ir. p. 48)7. Al mismo tiempo, y de manera inaugural en el campo local de estudios en juventudes, Manzano aventura brevemente una interpretación que incorpora a la diferencia de género entre las motivaciones que pudieron haber traccionado la participación de las y los jóvenes secundarios en las manifestaciones que se producían en Buenos Aires y otras ciudades, en solidaridad con las de Catamarca. Motivo que, de hecho, rebasaría la agenda clásica de

7 Las otras dos, señala Manzano, fueron las movilizaciones de 1991 impulsadas por los centros de estudiantes en reclamo de justicia por la muerte de Walter Bulacio (apaleado brutalmente por agentes de la Policía Federal en una razzia a la entrada de un recital de rock en Buenos Aires), que incluían, más extensivamente, un repudio a las políticas de "gatillo fácil" en tiempos en que se recrudecía la estigmatización de los varones jóvenes de sectores populares en tanto sujetos "peligrosos". Vale decir, como "pibes chorros", como señalamos al inicio. Y, por último, la masiva participación de estudiantes en apoyo a la escuela pública y en contra de las intenciones reprivatizadoras que aparejaba la aplicación de la Ley Federal de Educación, a mediados de 1992 (2011, pp. 28-49). 
las reivindicaciones del colectivo estudiantil de esos años: “(...) es difícil negar la identificación que muchos y, especialmente, muchas habrán sentido con la víctima", afirma la autora (48). De hecho, la propia madre de María Soledad puso varias veces en valor el protagonismo de las chicas en aquellos intensos y dolorosos años de insistentes marchas contra la impunidad de los poderosos de aquella provincia.: "(...) tengo un reconocimiento eterno a sus ex compañeras -dijo en un reportaje periodístico en 2015, cuando se cumplieron veinticinco años del crimen-, porque siendo adolescentes, chicas de 17 años, salieron y enfrentaron a todos. Ellas fueron las precursoras de todo esto, de todos los pedidos de justicia y de la justicia parcial que tuvimos después" (Clarín, 6/9/2015, digital).

Siguiendo esta línea, hay un aspecto más que me gustaría resaltar a partir de este caso, en el marco de las reflexiones que procuro aportar a la discusión sobre las formas que asume el lazo entre género y juventud en un determinado contexto, y su impacto en nuestro quehacer investigativo. Refiere a los modos históricos de figuración de la condición juvenil y a sus posibilidades de visibilización y conversión en objeto de reflexión social y científica. Porque así como las relaciones de fuerza que tramaban el contexto en el que tuvo lugar la muerte de María Soledad no se articularon de manera prioritaria en torno de la connotación sexual y/o de género del crimen sino alrededor de la respuesta social que despertó y de la lectura política que se hizo inmediatamente de ella ${ }^{8}$, la condición etaria y juvenil coaguló casi de modo exclusivo en la representación de la joven en tanto "alumna" de un colegio católico, o directamente como "estudiante secundaria".

Si bien es cierto, como explican Sandra Gayol y Gabriel Kessler, que "la sospecha sobre la moralidad de las mujeres, sobre cierta responsabilidad y culpa por sus asesinatos, recorrió todo el caso" (2018, p. 92), las dos imágenes que se difundieron de María Soledad y que la inmortalizaron en su condición de víctima "de la impunidad" y "de la corrupción del poder político" no estuvieron nunca en línea con la lectura previsible del sentido común reaccionario asociadas al ejercicio de la sexualidad por parte de las mujeres jóvenes. Es decir, no mostraban a una chica "sexy" y divertida, ni en una fiesta con amigas, ni bebiendo alcohol, ni siquiera al lado de algún varón en alguna presunción de goce. Imágenes todas ellas que en manos de los medios de comunicación podrían haber devenido -como aún ocurre- en indicios para la inferencia de una vida licenciosa, hipersexualizada o proclive a los excesos y donde, además, la condición juvenil femenina suele aparecer inscripta en esa representa-

8 Un primer trabajo reflexivo en clave feminista y al calor de los acontecimientos políticos que desató el caso María Soledad fue el de Silvia Chejter, quien en un texto de ese mismo 1990 escribió: "En las Marchas del Silencio aparece el imaginario de la violación, pero es la corrupción la que articula el pedido y el reclamo. El nepotismo como sistema de gobierno y no los abusos que sufren las mujeres como mujeres de Catamarca fueron enjuiciados y condenados" (Chejter, 1990 en Gayol y Kessler, 2018, p. 90). 
ción pregnante y estandarizada de vitalidad sin límites que, con frecuencia y de manera casi "premonitoria" en ese tipo de discursos, encuentra un coto en la propia muerte (Elizalde, 20I5b, p. I3). Por el contrario, la primera foto de la joven que circuló y que fue la más difundida a lo largo del tiempo fue una de ella en el colegio, con el uniforme escolar, cara lavada y pelo semi recogido, en medio de otras dos compañeras de división, todas sonrientes. La segunda, de menor circulación, una en la que lleva un vestido arreglado, de cuello cerrado y falda debajo de la rodilla, en un exterior, y sin compañía. Es decir que María Soledad, antes que "joven", o chica "fácil o "provocativa" fue construida como "estudiante". Ese fue, de hecho, el significante que le dio existencia pública una vez muerta; así se la pensó y nombró en su calidad de víctima. Como una estudiante que portaba uniforme y se reía entre amigas, y que la noche fatal de su violación y asesinato había ido al baile organizado por compañeras/os de su escuela con los zapatos que usaba todos los días para ir al colegio, porque su familia vivía con lo justo. Y así fue como se la consagró en el imaginario colectivo, al punto de devenir una suerte de ícono sacro-popular de la condición estudiantil.

De hecho, en un lugar donde fue encontrado el cadáver, y a instancias del Centro de Estudiantes de su ciudad natal, se construyó un monolito en su honor. Y unos años después, en el décimo aniversario de su muerte, se emplazó una escultura alegórica que sostiene, en una mano una antorcha en alto y en la otra, apoyada en el piso, una balanza de dos platos, como el símbolo de la Justicia. Desde mediados de I99o el lugar recibe cientos de visitas por año de peregrinos y lugareños que llegan hasta ahí a dejarle flores, estampas religiosas y pedidos de amparo para el hogar y auxilio en asuntos amorosos. Pero quienes más concurren son las y los jóvenes, que le dejan carpetas, hojas y cartucheras escolares. Se acercan a invocar su protección y a solicitar que les vaya bien en los exámenes de la escuela, así como a dejar sus útiles cuando terminan las clases, como gesto de agradecimiento por haber aprobado el año. La "santita", como le dicen en Catamarca (La Nación, 8/9/1996. digital), se convirtió de este modo en la protectora del estudiantado, condición que refrendó su propia madre $^{9}$.

Ahora bien ¿qué conocimientos aporta este caso, ocurrido hace poco más de 25 años? ¿Qué nos dice sobre los modos en que un contexto articula, en determinado momento (social, cultural, epocal) ciertas diferencias culturales, como las de edad, género y sexualidad, y produce a partir de ello una retórica de "iluminación" (Olivera, I999) y/o fijeza o delimitación discursiva de esas

9 En declaraciones a la prensa nacional Ada Morales relató: "Ayer vino una mamá a pedirme una foto de mi Sole, porque dice que el hijo le pide a María Soledad que lo ayude cuando estudia y siempre le va bien. Que le tiene fe como estudiante. Yo le voy a dar la foto a la señora. Si a ellos les hace bien, a mí también" (Clarín, 6/9/2015, digital). 
posiciones de sujeto en el espacio público?

Como indicamos, el caso María Soledad interpeló al poder porque institucionalizó una interrogación y una demanda de la sociedad que encontraron en aquella coyuntura una condición de emergencia, pero éstas no fueron principalmente del orden del repudio a una muerte en tanto crimen de género, ni al hecho de que la asesinada fuera una joven. Es decir, en aquellos años y por un buen tiempo no hubo una lectura hegemónica sobre la dimensión moralmente aleccionadora e indudablemente patriarcal de la violencia de género perpetrada sobre el cuerpo de la chica, ni sobre su vínculo crítico con la edad, sino más bien la idea de que la indignación por su muerte condensaba un sordo malestar en términos de opresión de clase, dominio autoritario y hartazgo ante la ostentosa impunidad de una elite criolla frente a una mayoría de incontables. Es decir, de los que no cuentan o, en palabras de Jacques Rancière (1996), de los que constituyen la parte de los sin parte. En este sentido, la imagen de una estudiante "común" muerta a manos de "los hijos del poder", como se llamó a los agresores, apenas si fue débilmente articulada a un incipiente reparo en la condición femenina de la víctima, pese a que -insistimos- los excesos perpetrados en su cuerpo hacían explícito el sesgo sexualizado y generizado de aquel delito.

Con todo, esta difuminación del vínculo entre género y edad no fue privativa de la agenda mediática y la opinión pública más extendida. El campo de los estudios en juventud de aquellos años '9o tampoco pudo hacer foco en dicha articulación, incluso ante un acontecimiento como éste que, parafraseando a Pierre Nora (1985) en su definición de événement [acontecimiento], atestiguó no tanto lo que tradujo "literalmente" como lo que reveló, no tanto lo que fue como lo que desencadenó: un desgarro del tejido social, una "ruptura" que puso en tela de juicio el equilibrio sobre el que estaba fundada aquella sociedad local. ¿Cómo interpretar estas ausencias en un ámbito científico y académico consagrado a la indagación de la juventud; al relevamiento de las prácticas que protagonizan los sujetos que encarnan esta condición; a la exploración de las transformaciones que produce su estar en el mundo en cada momento histórico? Como hemos señalado en distintas oportunidades (Elizalde, 2006, 20II, 20I5a) responder este tipo de preguntas nunca ha tenido que ver con meramente denunciar una falta o con señalar "responsables" sino con intentar desarmar los dispositivos epistemológicos -que son ideológicos- que están en la base de ciertas acciones, decisiones y procesos vinculados con la producción de conocimiento. Y, a la vez, con subrayar la importancia de dotar al campo de estudios en juventudes de una perspectiva teórica y política feminista en tanto forma incisiva de crítica cultural (Richard, 2009) y espacio de revisión y cuestionamiento del carácter múltiple de la opresión en la que el género se articula con otras distinciones.

\section{DE “LOS HIJOS DEL PODER" A “LAS HIJAS DE LA REVOLUCIÓN”}


El 9 de mayo de 20I5, apenas unos días después de haber cumplido I4 años, Chiara Páez se juntó con unas amigas en la casa de una de ellas, en la ciudad de Rufino, provincia de Santa Fe, donde vivía. Luego, a medianoche, se encontró con su novio Manuel Mansilla, de 17 , en el galpón ubicado en el patio de atrás de la casa del joven, como habían quedado. Cursaba un embarazo de dos meses y él lo sabía. Al principio la voluntad de ambos fue interrumpirlo, pero al parecer esa noche la chica insinuó la idea de continuar con la gestación. Nunca volvió a su casa y sus padres salieron desesperados a buscarla por todo el pueblo. Su cuerpo fue encontrado al otro día, enterrado en un pozo al fondo de la casa donde el chico vivía con su madre, su padrastro y sus abuelos, quienes estaban en la vivienda cuando, a escasos metros de allí, en el galpón, el joven golpeó a la chica, le cortó el cuello y continuó con la golpiza hasta provocarle la muerte. Luego la enterró. La autopsia indicó la presencia de una droga abortiva en la sangre de Chiara. Por su muerte fueron procesados tanto su novio como el resto de su familia, sospechados de ser partícipes necesarios de los delitos de homicidio agravado por el vínculo, femicidio y aborto no consentido. Finalmente solo se comprobó la culpabilidad del chico y casi tres años después del hecho fue condenado a veintiún años de cárcel. En el fallo judicial el crimen fue calificado como "espeluznante" y se explicitó que Chiara había sido asesinada "por su condición de mujer" (Página I2, 8/9/20I7, digital). Su muerte venía precedida por otros nueve femicidios ocurridos solo en su provincia desde enero de aquel 20I5, y de varios casos resonantes de otras adolescentes asesinadas cruelmente en distintos lugares del país ${ }^{10}$, cuyo total nacional de homicidios por razones de género llegó, ese año, a 286.

Como el de María Soledad, el crimen de Chiara no era el primero en su tipo, ni lamentablemente tampoco sería el último. Más bien integraba una ominosa serie que venía in crescendo. Pero inesperadamente, la brutalidad de su asesinato y el hartazgo e indignación generalizados frente a los anteriores convirtieron a su muerte en un nuevo punto de giro en la historia argentina. El caso no sólo instaló la urgencia de un gesto mancomunado de repudio contras la violencia de género sino que provocó la adhesión espontánea de miles y miles de mujeres y jóvenes a una marcha impulsada por un grupo de periodistas y artistas, apenas tres semanas después del hallazgo del cuerpo, bajo la consigna de \#NiUnaMenos. De este modo, el 3 de junio de 2015 más de 300 mil mujeres, con un alto porcentaje de jóvenes, marcharon junto a organizaciones feministas, sindicales y de derechos humanos a la Plaza del Congreso, en Buenos Aires, con repercusiones en varias ciudades del país. Desde entonces, la fecha es cita

10 Entre otros, los crímenes de Melina Romero, de 17 años, abusada y muerta por golpes y sofocamiento en septiembre de 2014; su cuerpo fue hallado un mes después de su desaparición dentro de una bolsa de basura al borde de un arroyo en la localidad bonaerense de José León Suárez; y el de Daiana García, de 19 años, muerta por asfixia en la localidad de Lavallol, en el conurbano, en marzo de 2015, quien fue encontrada al costado de una ruta, también dentro de una bolsa de residuos, semidesnuda, con una media en su boca. 
obligada para la visibilización de la imperiosa necesidad del colectivo de mujeres de ser escuchadas en su demanda de justicia ante los casos impunes, una más efectiva intervención del Estado frente a la multiplicación de estas violencias, y de un cambio cultural para la erradicación del machismo y la misoginia que están en su origen. A su vez, el movimiento originado a partir de esta primera marcha multitudinaria habilitó la emergencia de movilizaciones masivas en numerosos países de América Latina y en algunos de Europa. Asimismo, convirtió al concepto de "femicidio" en una palabra cotidiana que empezó a circular transversalmente -desde el ágora de los medios de comunicación a la mesa familiar-, y puso al feminismo "en boca de todos/as", en tanto praxis política que hizo posible este reclamo y esta conmoción cultural" ${ }^{\text {II }}$ Pero sobre todo, que encontró en las jóvenes una enorme adhesión y voluntad colectivas para devenir las voces y los cuerpos que hoy encarnan un proyecto de transformación de las jerarquías de género en pos de la equidad, de interpelación a los poderes públicos para el ejercicio pleno de la ciudadanía, y de emancipación del deseo respecto de los mandatos patriarcales.

En el presente, aquellas condiciones de coyuntura del primer \#NiUnaMenos, impulsado por la indignación que causó la muerte de Chiara, se traducen en una formación social emergente en la que un universo amplio de chicas -sobre todo, estudiantes secundarias y universitarias, de clase media, de grandes centros urbanos- se siente parte de una gran "marea feminista". Como tales, toman masivamente las calles al grito de "Vivas nos queremos", enarbolan el pañuelo verde de la legalización del aborto, lideran centros de estudiantes con una agenda de género como prioridad, promueven el lenguaje inclusivo, militan estos temas en las redes sociales, y estremecen las lógicas institucionales de las escuelas, las familias y la propia política. Son, así, las protagonistas de una "revolución" en materia de género, sexualidad y derechos que, con foco en las "pibas" y en la reconfiguración y actualización que realizan del legado combativo de la generación de sus madres, recibe coloquialmente la denominación de "la revolución de las hijas" (Peker en Fink y Rosso, 20I8, p. Io). Aquellas -casi un millón- que en la jornada histórica del tratamiento del proyecto de ley para la interrupción voluntaria del embarazo en la Cámara de Diputados decidieron no sólo seguir en las calles, frente al Congreso Nacional, acompañando el debate parlamentario de más de 22 horas, sino permanecer en vigilia esa noche helada del I3 de junio de 20I8, con la convicción visceral de estar sosteniendo una lucha por un derecho colectivo -el acceso al aborto legal, seguro y gratuitocuyo ejercicio les cambiaría la vida, y el futuro ${ }^{12}$. Para Luciana Peker, periodista que acuñó la metáfora de "la revolución de las hijas", las jóvenes despliegan hoy una acción política en el terreno de los géneros y las sexualidades que puede pensarse, en efecto, como del orden de una transformación radical en estos

11 La frase que sintetiza este diagnóstico fue "el feminismo lo hizo".

12 Agradezco a Silvia Delfino sus aportes y el haber podido discutir con ella esta idea. 
asuntos. En sus palabras, estos activismos juveniles llegan incluso a reescribir "la Noche de los Lápices, la laica y la libre, la reforma universitaria, el Mayo del '68 y la Noche de los Bastones Largos porque ellas ahora son protagonistas, como estudiantes, de hacer del saber un poder, de poder y querer que la imaginación tome el poder, de rechazar la represión y de pedir más derechos para todos, pero -también- para todas, porque no es cierto que los varones, en la conducción secundaria o estudiantil, las representen igual, [más bien] tomaban su voz como propia o les daban una entidad singular a la prepotencia machista que las pateaba en la cara" (p. iı)

De este modo, en un clima de época permeable a un discurso reinvidicativo de derechos -que las chicas viven como propio- en el campo de los géneros, la disidencia sexual, el placer, la autonomía de los cuerpos, y la salud sexual y reproductiva, su participación en la escena social y mediática ha ganado, pues, indudable centralidad. La nueva configuración pública que construyen en torno de su feminidad juvenil encuentra condiciones específicas de enunciación, "iluminación" y articulación de las diferencias de género y edad, en cruce con la clase, que "hablan" del trazado de una coyuntura y de un tiempo cultural que, por fin, les pertenece. Decimos, así, que hoy las chicas "forman parte de una generación que goza de logros decisivos en materia de género y sexualidad plasmados en un conjunto significativo de leyes que fueron resultado de años de luchas feministas por parte de mujeres que las precedieron largamente en la ocupación del espacio público para hacer oír sus reclamos" (Elizalde, 20I8, p. 23). Pero, al mismo tiempo, que estos avances son también "resultado de sus propias e intensas batallas en clave generacional", como las que encabezan en relación con el acoso callejero, el hostigamiento y el acoso sexual en las redes y en sus escuelas y universidades, los micromachismos, y la sanción de una ley de legalización y despenalización del aborto. En este sentido, las jóvenes van por todo. Como declaró Sofía Zibecchi, una dirigente estudiantil de i7 años, en el marco de las reuniones informativas organizadas por el plenario de comisiones de la Cámara Baja, el 3I de mayo de 20I8, antes del tratamiento del proyecto de ley en el recinto: "No estamos acá para pedirles permiso a las y los diputados si podemos abortar. Estamos acá para que hacerlo no nos cueste la vida"ז3.

Ahora bien, ¿qué relación hay entre el femicidio de Chiara y este "oleaje" verde de búsqueda de libertad, deseo y potenciación para el conjunto de las mujeres, que impulsan las más jóvenes? ¿Qué hizo posible que, ahora sí, una muerte como la suya fuera leída social y mediáticamente como un crimen de género cometido, además, contra una adolescente? Por un lado es claro que este "reconocimiento" público fue posible, como indicamos, por la disponibilidad jurídica en la Argentina, desde 20I2, del término "femicidio" para señalar la especificidad patriarcal de esta forma de violencia sobre los cuerpos femeninos

13 Desgrabación del registro filmado de la citada exposición oral. 
y feminizados ${ }^{14}$, y por su mayor circulación social desde entonces. Por otro, talló también el espesor histórico de las acciones y demandas feministas en relación con la violencia hacia las mujeres, que venían de varias décadas antes de la manifestación del \#NiUnaMenos, pero que encontraron en la coyuntura que abrió la muerte de Chiara, una oportunidad histórica, previamente imprevisible, para su anudamiento con un terreno cultural permeable a esas revindicaciones y para la multiplicación de estas marchas en todo el país, y en otros países de la Región. Pero a su vez, fue resultado de un cambio notorio en la significatividad conferida socialmente a las diferencias de género y sexualidad como diacríticos que intervienen, de modo cada vez más decisivo, en las batallas ideológicas entre fuerzas "progresistas" y "conservadoras", y en las discusiones por el sentido y alcance de la democracia real en nuestros países. En este marco, tanto la temática del aborto, sus discusiones a favor y en contra, como los repudios masivos contra la violencia machista, ingresaron a la agenda de los medios de comunicación habilitando incluso, en algunos casos, una novedosa apertura a las demandas de las mujeres a favor de la autonomía de sus cuerpos.

Ahora bien, si en el caso María Soledad el "difuminado" de su condición femenina en lazo con su edad fue al mismo tiempo resultado de una operación inversa de recorte y focalización en la condición masculina y etaria de "los hijos del poder", y un punto de articulación en una trama discursiva más amplia que estabilizó restrictivamente ciertas identidades y modos de ser joven, en la coyuntura actual, las dimensiones del género y la generación reciben el máximo de "iluminación" pública. Pues son las jóvenes quienes encarnan el sujeto social, cultural y político emergente en el que hoy se concentran todas las miradas. Tanto porque son la cara más visible y numerosa de las luchas de género en la Región como porque han comenzado a renovar fuertemente las formas, lenguajes y argumentos de dichos combates contra la desigualdad. Y con ello, lanzado una interpelación inocultable al campo de los estudios en juventudes, en términos de repertorio de objetos, modos de investigación y formatos de registro. La nueva formación social que propenden se asienta en una trama de relaciones, prácticas y sentidos generizados y sexualizados cuya especificidad desafía las agendas de indagación tal como las conocemos y organizamos hasta el momento, así como las epistemologías que vienen informando nuestro trabajo de estudio e intervención sobre las juventudes.

\section{UNA INTERROGACIÓN DE LOS CONTEXTOS}

14 En esta línea, la figura de "travesticidio" recortó su especificidad a partir de esta primera conquista feminista, y ganó legitimidad propia a partir del activismo LGBT. La aplicación inaugural de esta denominación ocurrió en oportunidad del juicio iniciado por el crimen de la militante trans Diana Sacayán, que culminó con sentencia de culpabilidad a su agresor, por travesticida. 
La pregunta que transversalizó este trabajo fue qué (nos) "dicen" los contextos sobre el vínculo entre género y juventud cuando los analizamos en tanto espacios de producción de condiciones y articulación entre prácticas, valores y sentidos. Es decir, como campos dinámicos de conexiones desiguales entre fuerzas heterogéneas "que buscan constantemente equilibrios temporales o estabilidades estructurales a través de una variedad de prácticas y procesos de lucha y negociación" (Grossberg, 2012, p. 59). En ese marco, emprendimos el análisis de dos coyunturas histórico-culturales -una, ubicada a inicios de la década de 1990, y otra, que llega hasta el presente-, que comparten un arco temporal muy próximo al tiempo de existencia de esta revista pero, sobre todo, que surcan una trayectoria clave del campo de los estudios en juventudes en América Latina, desde su decidido despegue, en el último decenio del siglo XX, hasta la actualidad. Recorrido que es también, finalmente, mi propio devenir intelectual en esta ámbito de quehacer científico.

Partimos asimismo de asumir que la forma en que delineamos un contexto depende de las preguntas que formulemos. Aquí, esa interrogación tuvo que ver con los modos en que cierto conjunto de prácticas y sentidos asociados a experiencias concretas de sujetos jóvenes operaron como "puerta de entrada" para explorar el carácter socio-histórico y político que adquieren las diferencias de género y sexualidad vinculadas a las juventudes en cada una de las coyunturas revisadas. $\mathrm{Al}$ respecto, el hecho de que las conexiones entre estas distinciones no hayan sido resaltadas en la interpretación social y mediática del caso María Soledad, ni examinadas, retomadas o advertida su invisibilización por parte de la investigación social en juventudes no significa, claramente, que el contexto en el que tuvo lugar aquel crimen -y su construcción narrativa- actuara por fuera de la malla de relaciones sociales "generizadas" y sexualizadas existente en dicha coyuntura. Del mismo modo, que estas diferencias sí hayan sido "iluminadas" y a la vez sean constitutivas de una preocupación social gestada a partir de la muerte de Chiara Páez, del movimiento \#NiUnaMenos que la indignación por ese caso desencadenó, y de la emergencia exponencial de las mujeres jóvenes como propulsoras de una "revolución" en estas materias no va necesariamente de la mano de una mayor complejización analítica y teórica-epistemológica alrededor de estos cruces en la investigación científica especializada en juventudes. En todo caso, ambas situaciones señalan cómo los contextos están lejos de ser meros escenarios que "marcan" con mayor o menor inexorabilidad a ciertas prácticas y sujetos con tal o cual "impronta" identitaria de una forma nítida, unívoca o permanente. Muestran, más bien, que ellos mismos son resultado y condición de un ensamblaje de múltiples líneas de fuerza, determinación y resistencia que producen un tipo de unidad o de totalidad una suerte de "estado de cosas"- siempre temporal, complejo y frágil que, en relación con las diferencias de edad, género y sexualidad que nos ocupan, organizan una cierta grilla de inteligibilidad -y por ende, de visibilidad o invisibilidad públicas- de estas distinciones en cada momento. De este modo, los contextos 
o coyunturas históricas, políticas e institucionales se revelan como elementos cruciales para comprender las ausencias y oscilaciones, así como los diálogos y los abordajes virtuosos que se han ido dando en el campo de los estudios en juventudes en nuestros países respecto de las distintas configuraciones de géneros y sexualidades vinculadas a las nuevas generaciones. No son, pues, lo que está "antes" o "después" de las prácticas juveniles estudiadas en cada momento, ni operan como "escenario", "telón de fondo" o visión ampliada o panorámica de lo estudiado en escala micro. Son, por el contrario, configuraciones en las que se hacen, deshacen y rehacen dichas prácticas y relaciones entre prácticas en múltiples conexiones, no inexorables ni permanentemente fijas -pese a, como dijimos, cierto estatus de estabilidad o naturalización que algunas parecen alcanzar por un cierto tiempo-, en respuesta a los intereses de determinadas posiciones de poder. Simultáneamente, como sostiene Lawrence Grossberg, las propias prácticas contribuyen también a la producción del contexto, en tanto una "experiencia de poder vivida a diario" (pp. 40-4I).

En este tipo de propuestas de análisis la teoría cobra valor no como fuente desde la cual plantear preguntas derivadas de intereses teóricos, sino a la inversa, como herramienta de lectura contextual, "como un recurso estratégico contingente" que asume los riesgos que implica investigar. Grossberg lo dice de manera directa: puesto que, en su perspectiva, "la teoría y el contexto se constituyen y se determinan mutuamente", ésta "debe usarse de modo estratégico para responder a problemáticas, luchas y contextos particulares" y para permitirnos "una mejor (re)descripción del contexto" (pp. 43 y 44). En línea con esto, se vuelve también clave la reflexión sobre el propio lugar del/la investigador/a, en tanto responsable de las preguntas que le formula a cada coyuntura (Hall, 20IO; Grossberg, 20I2). Sobre todo en tiempos como el presente, en el que los/as investigadores/as ya no somos más quienes interpelamos al mundo juvenil en pos de conocerlo mejor, sino quienes somos interpelados/as por las preguntas que ellos/as mismos/as, y el propio contexto que habitan, hacen.

Frente a ambos aspectos -el "quehacer" teórico y la autorreflevidad-, la teoría feminista tiene mucho que aportar. Al respecto, nunca está de más alejar los fantasmas de quienes la piensan como reducto o trinchera de lo "mujeril", como "exceso" o pretensión insaciable que todo lo devora o tritura con sus garras, figuraciones torpes e infantiles que se invocan para exorcizar los miedos que despierta la invitación efectiva a la revisar la propia posicionalidad en una clave absolutamente deconstructiva de toda certeza o privilegio. Como bien lo plantea Nelly Richard (2009), "la teoría feminista abarca el pluralmultidiferenciado del conjunto de identidades y diferencias que traspasan la simple oposición sexual al interconectar distintas coordenadas de poder, hegemonía, cultura y resistencia". De allí que este particular acento le permita al feminismo "usar el género no para reafirmar una 'propiedad' de la diferencia sexual, sino como una fuerza que impulsa cada territorio subjetivo a moverse creativamente entre centralidad y márgenes, entre unidad y fragmentación, entre autonomía y 
heteronomía" (p. 83). Invitación epistemológica que aquí también quisimos invocar.

$\mathrm{Si}$, efectivamente "el conocimiento siempre se basa en una relación visceral" (Grossberg, 20I2, p. 34) de forma tal que resulta imposible escindir asépticamente la búsqueda de rigor académico de la pasión y el compromiso social involucrados en ella, y si, junto a ello, sostenemos que el feminismo no es un sayo que se pone y se saca en las circunstancias oportunas sino un modo profundo de habitar la posición de investigador/a, sobre el final deslizo, entonces, un último señalamiento. Me interesa, pues, hacer notar cómo este juego de elementos ha tensionado no sólo los ejes analíticos propuestos aquí para el campo de los estudios en juventudes en relación con las diferencias de género y sexualidad, sino mi propio recorrido investigativo (desde mis venti-cortos años), como parte de las condiciones académico-institucionales y coyunturales más amplias que atravesaron -y nos atravesaron en- estos veinticinco años de historia común.-

\section{REFERENCIAS}

Alvarez, C. (2018). Lo juvenil y el género: pistas para su abordaje. En: C. Duarte y C. Álvarez (eds.), Juventudes en Chile. Miradas dejóvenes que investigan (pp.48-69). Santiago: Social-Edicicones, Universidad de Chile.

Chaves, M (2018). Tres apropiaciones (o más). Dialogando diez años después con el texto de Sergio Tonkonoff sobre pibes, choreo, ropa deportiva y la moral del amo. Cuestiones criminales, I(I), pp.I44-I55I. Quilmes: UNQUI.

Chejter, S (1990). La voztutelada. Violación y voyeurismo. Buenos Aires-Montevideo: Nordan Comunidad.

Duarte, C. (20r6). Genealogía del adultocentrismo. La constitución de un patriarcado adultocéntrico". En: C. Duarte y C. Álvarez (eds.), fuventudesen Chile (pp. 17-47) Santiago: Universidad de Chile.

Duarte, C. (2015). Lo juvenil en masculino: a medio camino entre alternativos y tradicionales. En: C. Feixa y P. Oliart (eds.), Juvenopedia. Mapeo dejuventudesiberoamericanas. Barcelona: Ned Ediciones.

Duarte, C. (20II). Privilegios patriarcales en varones jóvenes de sectores empobrecidos ¿cambio o acomodo?”. Revista de Estudios de Fuventud, (95), pp. 45-57. Madrid: Instituto Nacional de Juventud de España.

Elizalde, S. (2006). El androcentrismo en los estudios de juventud: efectos ideológicos y aperturas posibles. Última Década, I4(25), pp. 9I-IIo. Valparaíso: CIPDA.

Elizalde, S. (20iI). Introducción. En: Fóvenes en cuestión. Configuraciones de género y sexualidad en la cultura (pp. I3-19). Buenos Aires: Biblos. 
Elizalde, S. (2015a). Estudios de Juventud en el Cono Sur: epistemologías que persisten, desaprendizajes pendientes y compromiso intelectual. Una reflexión en clave de género. Última Década, 23(42), pp. I29-I45. Santiago de Chile: Proyecto Anillo Juventudes. Recuperado de: http://www.scielo. $\mathrm{cl} / \mathrm{pdf} /$ udecada/v23n42/arto7.pdf.

Elizalde, S. (20I5b). Tiempo de chicas. Identidad, culturay poder. Buenos Aires: Grupo Editor Universitario.

Elizalde, S. (20I8). Las chicas en el ojo del huracán machista: entre la vulnerabilidad y el 'empoderamiento'. Cuestiones Criminales, I(I), pp. 22-40. Quilmes: UNQUI. Recuperado de: https://docs.wixstatic.com/ugd/f $455 \mathrm{e} 4$ Igb5787oeb2e4I898beab788ef99749d.pdf

Fink, N. y Rosso, L. (20I8). Feminismo para fóvenas. Ahora que sí nos ven. Buenos Aires: Chirimbote.

Gayol, S. y Kessler, G. (2018). Muertes que importan. Una mirada sociohistórica sobre los casos que marcaron la Argentina reciente. Buenos Aires: Siglo XXI.

Grossberg, L. (2012). Estudios culturales en tiempo futuro. Cómo es el trabajo intelectual que requiere el mundo de hoy. Buenos Aires: Siglo XXI.

Hall, S., Critcher, C., Jefferson, T., Clarke, J., y Roberts, B. (1978). Policing the crisis. Mugging, the State and Law and Order. London: MacMillan.

Hall, S. (20IO). Estudios culturales y sus legados teóricos. En: E. Restrepo, C. Walsh y V. Vich (Eds.), Sin garantías. Trayectorias y problemáticas en estudios culturales (pp. 73-94). Instituto de Estudios Sociales y Culturales Pensar, Universidad Javeriana/ Instituto de Estudios Peruanos, Universidad Andina Simón Bolívar: Envión Editores.

Kessler, G. (2004). Sociología del delito amateur. Buenos Aires: Paidós.

Manzano, V. (20II). Cultura, política y movimiento estudiantil secundario en la Argentina de la segunda mitad del siglo XX. Propuesta Educativa, I(35), pp. $4 \mathrm{I}^{-} 5^{2}$.

Míguez, D. (2004). Los Pibes Chorros. Estigmay Marginación. Buenos Aires: Capital Intelectual.

Nora, P. (1985). La vuelta del acontecimiento. En: J. Le Goff y P. Nora (eds.), Hacer la historia (pp. 22I-239). Barcelona: Laia.

Olivera, G. (I999). Políticas de la restitución. Identidades y Luchas Homosexuales en Argentina. En: F. Forastelli y X. Triquell (comps.), Las marcas del género. Configuraciones de la diferencia en la cultura (pp. 67-84). Córdoba: CEA/Universidad Nacional de Córdoba.

Peker, L. (20I8). Las antiprincesas crecieron y ya son protagonistas. En: N. Fink y L. Rosso, Feminismo para fóvenas. Ahora que sínos ven (pp. 9-12). Buenos Aires: Chirimbote.

Rancière, J. (i996). El desacuerdo. Política y fllosofía. Buenos Aires: Nueva Visión.

Richard, N. (2009). La crítica feminista como modelo de crítica cultural. Debate feminista, 4o(20), pp. 75-85. Recuperado de: http://www.debatefeminista. 
com/descargas.php?archivo=lacritı226.pdf\&id_articulo=I226

Rodríguez Alzueta, E. (20I4). Temory control. La gestión de la inseguridad como forma de gobierno. Buenos Aires: Futuro Anterior.

Tonkonoff, S. (2007). Tres movimientos para explicar por qué los pibes choros visten ropa deportiva. En: VVAA, La sociología ahora, (pp. I5I-I64). Buenos Aires: Siglo XXI.

Williams, R. (2000) [1977]. Marxismoy Literatura. Barcelona: Península.

\section{NOTAS PERIODÍSTICAS:}

Matan a una joven en Catamarca (II de septiembre de 1990). Clarín, s/p.

La mamá de Soledad, a 25 años del crimen que hizo temblar a Catamarca (6 de septiembre de 20I5). Clarín. Recuperado de: https://www.clarin.com/ policiales/ada_morales-maria_soledad-columna-gambini_o_HkZlcu7twmx.html

El origen de las marchas del silencio (I8 de febrero de 2015). El Ancasti. Recuperado de: https://www.elancasti.com.ar/opinion/2015/2/I8/origen-marchas-silencio-25IO32.html

El clamor por justicia no se ha acallado (9 de septiembre de 2005). La Gaceta. Recuperado de: https://www.lagaceta.com.ar/nota/I2730I/policiales/ clamor-justicia-no-se-ha-acallado.html

Nadie oyó gritar a María Soledad Morales (8 de septiembre de i996). La Nación. Recuperado de: https://www.lanacion.com.ar/172804-nadie-oyo-gritar-a-maria-soledad-morales

María Soledad Morales: el brutal crimen que hizo caer a una dinastía feudal en los '9o (I7 de julio de 2018). La Nación. Recuperado de: https://www. lanacion.com.ar/2I56oog-maria-soledad-morales-el-caso-que-revoluciono-catamarca

Un crimen espeluznante ( 8 de septiembre de 2017). Página I2. Recuperado de: https://www.paginaI2.com.ar/6r678-un-crimen-espeluznante 